\title{
HUBUNGAN ANTARA SIKAP DENGAN PRAKTIK PENYULUHAN TENTANG ASI EKSKLUSIF KADER KESEHATAN DESA SIAGA AKTIF
}

\author{
Titi Mursiti ${ }^{1}$, Sri Setiasih ${ }^{2}$, Ana Sundari ${ }^{3}$ \\ 1,2,3 UPP Kampus Kendal, Poltekkes Kemenkes Semarang, Indonesia
}

Email: titimursiti@ymai.com

\begin{abstract}
Death in newborn can be prevented by breast feeding. Infants who are breastfed early will begin their lives in the healthiest way. The prelimenary survey was conducted on 10 active health cadres in Peron Village and Kedungboto Village, 6 of whom had less supportive attitudes towards exclusive breeastfeeding. The purpose of this study was determine the relationship between attitudes and exclusive breastfeeding practice in active village health cadres. This type of research is observational analytic, which is descriptive quantitative by using a cross sectional approach. The data source is primary data and secondary data. The Sample of this study is the total population, a total of 50 respondents. The results showed that attitudes abouit exclusive breastfeeding was classified as a good with a score of 6-8 by $68 \%$ (34 people).There is asignificant relationship between attitudes with the practice of exclusive breastfeeding counseling for active villages health cadres, advice for policy makers to develop programs for seminars or training on exclusive breastfeeding for health cadres of in active alert villages
\end{abstract}

Keywods: Attitudes, Practice, Cadres, Exclusive Breast feeding 


\section{PENDAHULUAN}

Pembangunan kesehatan merupakan salah satu tujuan pembangunan nasional negara untuk menciptakan masyarakat yang adil dan sehat dan sejahtera. Indikator keberhasilan dari pembangunan kesehatan adalah dilihat dari jumalh angka kematian ibu dan angka kematian Bayi. Determinan dari angka kematian baru ditentutakan oleh berbagai faktor dari faktor ibu kesiapan ibu dalam kehamilan, keadaan gizi dan perawatan masa antenatal serta proses persalinan dan masa pasca salin, sedangkan dari faktor bayi usia kehamilan, berat badan kondisi fisik serta asupan gizi yang tepat terutama pemberian Air susu ibu. Kematian pada bayi baru lahir dapat dicegah dengan pemberian ASI. Bayi yang mendapatkan ASI sejak dini akan lebih sehat dan memulai kehidupannya dengan cara yang paling sehat sehingga angka kematian bayi dapat diturunkan. (Lestariningsih and Budi Susila Duarsa, 2013)

Kematian bayi di Indonesia dipengaruhi oleh beberapa factor yang berhubungan dengan perawatan bayi baru lahir dan pemenuhan kebutuhan dasar bayi. Pada saat bayi dilahirkan seluruh kebutuhan tergantung dari pemberi asuhan yang ada disekitarnya. Beberapa kasus kematian bayi karena penanganan yang kurang tepat ada bayi yang mengalami asfiksia premature maupun BBLR sehingga penting untuk mengetahui kebutuhan dasar bayi baru lahir dan cara pemenuhananya (Kemenkes RI, 2013). Pemerintah melalui program MDg-s 2015 menargetkan angka kematian bayi kurang dari 35 per 1000 kelahiran hidup namun sampai saat ini angka tersebut masih belum tercapai dengan sempurna. Faktor pemberian ASi yang merupakan satu satunya nutrisi utama dan pertama yang dibutuhkan bayi baru lahir seringkali tidak didapatkan bayi. hasil penelitian dari journal keperawatan klinik 2013 terdapat hubungan signifikan dari frekuensi menyusui dengan berat badan bayi. bayi baru lahir rentan untuk mengalami penurunan berat badan sehingga dengan pemberian asi ekslusif berat badan bayi akan dapat mencapai maksimal dan kesejahteraan bayi meningkat. inisiasi menyus dini merupakan salah satu program yang perlu terus dilakukan agar bayi dan ibu selamat (Hastuti and Wijayanti, 2017)

Kematian pada bayi baru lahir dapat dicegah apabila bayi disusui sejak hari pertama kelahiran, maka angka kematian bayi di bawah 28 hari dapat diturunkan hingga $22 \%$, Begitu juga dengan angka harapan hidupnya dapat meningkat menjadi 22 \% jika bayi disusui pada 1 jam pertama setelah kelahiran. Sedangkan menurut UNICEF bahwa sebanyak 30.000 kematian bayi yang terjadi di Indonesia dan 10 juta kematian anak balita yang terjadi di dunia setiap tahunnya dapat dicegah dengan pemberian ASI eksklusif selama 6 bulan sejak kelahirannya. dalam memberikan asi tergantung dari 
kedekatan antara ibu dan bayi yang dilahirkan. tenaga kesehatan dapat membantu dan memotivasi tetapi tidak selalu terdapat hubungan antara dukungan dari tenaga kesehatan terhapa ibu dalam memberikan asi eklusif. perasaan kasih sayang ibu dan ank akan menumbuhkan motivasi ibu dalam memberikan Asi ekslusif. (Suriani, 2017) Indonesia menargetkan $80 \%$ ibu dapat memberikan ASI eksklusif selama enam bulan pertama hidup bayi dan diteruskan dengan pemberian ASI bersama makanan pendamping ASI ( MP-ASI) yang sesuai kualitas dan kuantitasnya sampai anak berusia 2 tahun atau lebih. Keberhasilan Program ASI Eksklusif tidak hanya tergantung pada ibu menyusui tetapi juga diperlukan kerja sama secara lintas sektor dan terpadu serta adanya peran serta dari masyarakat.Pelayanan kesehatan selama masa kehamilan, persalinan, nifas sangatlah penting bagi keberlangsungan kesehatan ibu dan bayi, termasuk sebagai upaya menurunkan AKI dan AKB. Pelayanan kesehatan pada ibu menjadi prioritas utama dalam pengembangan kesehatan nasional maupun global.Maka dari itu Pemerintah Indonesia telah menargetkan peningkatan cakupan layanan kesehatan sebagaimana tercantum dalam Rencana Pembangunan Jangka Menengah Nasional (RPJMN) 2015.

dalam meningkatkan peran serta masyarakat untuk mendukung program pemberian asi melalui pembentukan Desa siaga yang memiliki visi misi Indonesia sehat yang intinya memberdayakan masyarakat agar mau dan mampu untuk hidup sehat. berbagai elemen perlu disiapkan diantaranya kader kesehatan .(Triyono and Wibowo, 2018)

Peran serta masyarakat dalam desa siaga dapat dilakukuan oleh kader kesehatan terutama yang bertanggung jawab dalam penyuluhan manfaat asi ekslusif. kader keehatan merupakan sosok yang sukarela melayani masyarakat sekitarnya dan dikenal leh masyarakat serta memahami kondisi masyarakat disekitar tempat tinggalnya. tugas kader kesehatan menjadi mitra bagi tenaga kesehatan dalam membangun desa siaga terutama untuk menurunkan angka kematian bayi melalui promosi pemberian asi ekslusif. (Triyono and Wibowo, 2018) Berdasarkan data dari tingkat Nasional dan data beberapa kota di Indonesia. Menurut data dari Susenas pada tahun 2016 pencapaian ASI Eksklusif sebesar $51,8 \%$. Jumlah tersebut meningkat pada tahun 2017 menjadi 57,8 \%. Sedangkan data dari Dinas Kesehatan Provinsi Jawa Tengah tahun 2017 adalah 54,4 \%, tahun 208 meningkat sedikit menjadi 54,6\%,Data Dinas Kesehatan Kabupaten Kendal pada tahun 2017 sebesar 46 \%,dan pada tahun 2018 turun menjadi $45,9 \%$.

Berdasarkan survey pendahuluan di Desa Peron dan kedungboto terdapat kader 50 orang kader kesehatan. 5 dari 10 orang menyatakan belum memahami tentang 
pemberiam ais susu ibu, Berdasarkan latar belakang tersebut di atas maka peneliti tertarik melakukan penelitian yang bertujuan untuk mengetahui hubungan antara sikap dengan praktik penyuluhan Asi Ekslusif Kader Kesehatan di desa siaga aktif Desa Kedungboto dan Desa Peron Kecamatan Limbangan Kabupaten Kendal . .

\section{Metode penelitian}

Jenis penelitian ini adalah observasional, yang bersifat deskriptif analitik. Pendekatan yang digunakan adalah croseksional. Populasi dalam penelitian ini adalah seluruh kader yang berada di desa siaga aktif Desa Peron dan Kebungboto Kecamatan Limbangan kabupaten kendal. metode pengambilan sampel dalam penelitian ini adalah mengunakan total populasi dengan jumlah sampel 50 orang kader. pengumpulan data dilaksanakan pada bulan Agustus 2019 bersamaan dengan kegiatan pembinaan kader kesehatan di balai Desa peron Kecamatan Limbangan kabupaten kendal. Jenis data yang digunakan adalah Penggumpulan data primer yang berisi tentang karakteristik kader, sikap dan praktik penyuluhan asi ekslusif. Instrument dalam penelitian ini berupa kuesioner yang diisi oleh responden setelah menandatangani form informed consent sebagai bukti persetujuan dalam kegiatan penelitian. Teknik pengolahan data terdiri dari langkah editing.coding dan tabulating. setelah itu data selanjutnya dilakukan analisa yang digunakan. uji normalitas, karena jumlah sampel besar ( $\geq 50$ ) maka di gunakan analisis Kolmogorov Smirnov. Kriteria distribusi data dikatakan normal apabila nilai kemaknaan (nilai $p$ ) >0,05. selanjutnya dilakukan uji statistik dengan analisa Analisa bivariat dilakukan menggunakan analisa inferensial atau uji statistik. Uji ini dilakukan terhadap dua variabel, yang bertujuan untuk mengetahui hubungan masing-masing variabel bebas (umur, pendidikan, lama menjadi kader, pelatihan, sikap) dengan variabel terikat (praktik penyuluhan tentang ASI Eksklusif kader kesehatan desa siaga aktif). Jika data hasil penelitian berdistribusi normal maka digunakan uji statistik parametrik korelasi Pearson, jika data hasil penelitian berdistribusi tidak normal maka menggunakan uji statistik alternatifnya yaitu korelasi Rank Spearman ${ }^{24}$. Adapun keputusan uji dari variabel bebas dengan variabel terikat adalah jika nilai $p<0,05$ artinya terdapat korelasi yang bermakna antara dua variabel yang diuji sedangkan jika nilai $p>0,05$ artinya tidak terdapat korelasi yang bermakna antara dua variabel yang diuji. Sehingga dari analisa uji statistik yang dilakukan akan diketahui variabel bebas mana yang berhubungan (nilai $p<0,05$ ) dengan variabel terikat

\section{HASIL PENELITIAN DAN BAHASAN}

\section{A. Hasil Penelitian}

Analisa univariat disajikan berupa hasil mean,minimum, maximum, dan standar deviasi. Diuraikan juga mengenai 
distribusi frekuensi pada identitas responden dan variabel penelitian yaitu : pengetahuan kader tentang ASI Eksklusif, sikap kader tentang ASI Eksklusif, dan praktik penyuluhan ASI Eksklusif kader kesehatan desa siaga aktif, dengan hasil sebagai berikut :

Tabel 1. Nilai Mean, Minimum, Maximum, dan Standar Deviasi Variabel Penelitian

\begin{tabular}{|c|c|c|c|c|c|c|}
\hline $\mathbf{N}$ & $\begin{array}{c}\text { Variabel } \\
\text { Penelitia } \\
\text { n }\end{array}$ & Desa & Mean & $\begin{array}{c}\text { Mini } \\
\mathrm{mu} \\
\mathrm{m}\end{array}$ & $\begin{array}{c}\text { Maxi } \\
\mathrm{mu} \\
\mathrm{m}\end{array}$ & $\begin{array}{c}\text { Stan } \\
\text { dar } \\
\text { Devia } \\
\text { si }\end{array}$ \\
\hline \multirow[t]{3}{*}{1} & Sikap & Peron & 28,28 & 3,01 & 22 & 34 \\
\hline & $\begin{array}{l}\text { kader } \\
\text { tentang }\end{array}$ & $\begin{array}{l}\text { Kedun } \\
\text { gboto }\end{array}$ & 29,00 & 3,84 & 23 & 38 \\
\hline & $\begin{array}{l}\text { ASI } \\
\text { Eksklusif }\end{array}$ & Total & 28,64 & 3,43 & 22 & 38 \\
\hline \multirow[t]{3}{*}{2} & Praktik & Peron & 5,80 & 1,12 & 4 & 8 \\
\hline & $\begin{array}{l}\text { penyuluh } \\
\text { an ASI }\end{array}$ & $\begin{array}{l}\text { Kedun } \\
\text { gboto }\end{array}$ & 7,04 & 1,51 & 4 & 8 \\
\hline & Eksklusif & Total & 6,42 & 1,46 & 4 & 8 \\
\hline
\end{tabular}

Tabel 1 menunjukkan bahwa nilai ratarata sikap kader tentang ASI Eksklusif sebesar 13,10 yang termasuk dalam kategori baik, tetapi masih terdapat kader yang memiliki nilai minimim yaitu 10 yang Kader yang berasal dari Desa Peron Maupun Desa Kedungboto memiliki sikap tentang ASI Eksklusif yang hanpir sama yaitu dengan nilai rata-rata masing-masing sebesar 13,08 dan 13,12.

Pada Tabel 1 menunjukkan nilai rata-rata praktik kader tentang ASI Eksklusif sebesar 28,64 yang termasuk dalam kategori baik, namun demikian masih terdapat kader yang memiliki nilai minimim yaitu 22 yang berarti masih terdapat sikap kader tentang ASI Eksklusif tergolong sedang atau cukup baik.
Sedangkan praktik kader tentang ASI eksklusif yang berasal dari Desa Kedungboto rata-rata 29,00 sedikit lebih tinggi dibandingkan dengan kader yang berasal dari Desa Peron dengan nilai ratarata sebesar 28,28 .

Praktik penyuluhan ASI Eksklusif yang dilakukan oleh kader meliputi materi yang berisi penjelasan dan penyuluhan tentang manfaat, kandungan dan kelebihan dalam ASI, manfaat menyusui baik bagi ibu maupun bayinya, disamping bahaya pemberian susu botol kepada ibu dan keluarganya yang dilakukan oleh kader atau anggota masyarakat yang dipilih dari dan olehuntuk masyarakat, mau dan mampu bekerja bersama dalam berbagai kegiatanmasyarakat secara sukarela. Tabel 1 menunjukkan nilai rata-rata praktik penyuluhan ASI Eksklusif oleh kader sebesar 6,42 yang termasuk dalam kategori baik, namun demikian masih terdapat kader yang memiliki nilai minimim yaitu 4 yang berarti praktik penyuluhan ASI Eksklusif yang dilakukan kader tergolong sedang atau cukup baik. Kader yang berasal dari Desa Kedungboto melaksanakan praktik penyuluhan ASI Eksklusif dengan rata-rata 7,04 lebih tinggi dibandingkan dengan kader yang berasal dari Desa Peron dengan nilai rata-rata sebesar 5,80 .

Hasil analsisis univariat yang berbentuk distribusi frekuensi dijelaskan sebagai berikut: 
Tabel 2 Distribusi frekuensi Responden Berdasarkan Umur Umur Frekuensi Persentase

\begin{tabular}{ccc} 
(Tahun) & (orang) & $(\%)$ \\
\hline$<30$ & 6 & 12 \\
$30-39$ & 23 & 46 \\
$40-49$ & 11 & 22 \\
$\geq 50$ & 10 & 20 \\
\hline Total & 50 & 100
\end{tabular}

Berdasarkan data Tabel 2 Dijelaskan bahwa kader kesehatan desa siaga aktifyang berasal dari Desa Kedungboto dan Desa Peron Kecamatan Limbangan Kabupaten Kendal, sebagian besar berumur $30-39$ tahun yaitu sebanyak $46 \%$ (23 orang) sedangkan yang paling sedikit berumur kurang dari 30 tahun yaitu sebanyak $12 \%$ (6 orang),

Tabel.3 Distribusi Frekuensi responden berdasarkan pendidikan

\begin{tabular}{ccc}
\hline Pendidikan & $\begin{array}{c}\text { Frekuensi } \\
\text { (orang) }\end{array}$ & $\begin{array}{c}\text { Persentase } \\
(\%)\end{array}$ \\
\hline SD & 13 & 26 \\
SMP & 29 & 58 \\
SMA & 8 & 16 \\
\hline Total & 50 & 100 \\
Berdasarkan & data & Tabel
\end{tabular}

Dijelaskan bahwa kader kesehatan desa siaga aktifyang berasal dari Desa Kedungboto dan Desa Peron Kecamatan Limbangan Kabupaten Kendal, sebagian besar berpendidikan SMP yaitu sebanyak $58 \%$ (29 orang), $16 \%$ (8 orang) yang berpendidikan SMA. Kondisi ini menunjukkan bahwa pendidikan kader kesehatan desa siaga aktif di Desa Kedungboto dan Desa Peron Kecamatan Limbangan Kabupaten Kendal masih tergolong rendah.
Tabel 4Distribusi frekuensi Responden Berdasarkan Lama Menjadi Kader

\begin{tabular}{ccc}
$\begin{array}{c}\text { Lama Menjadi } \\
\text { Kader } \\
\text { (tahun) }\end{array}$ & $\begin{array}{c}\text { Frekuensi } \\
\text { (orang) }\end{array}$ & $\begin{array}{c}\text { Persentase } \\
(\%)\end{array}$ \\
\hline$<1$ & 6 & 12 \\
$1-5$ & 14 & 28 \\
$6-10$ & 15 & 30 \\
$11-15$ & 7 & 14 \\
$>15$ & 8 & 16 \\
\hline Total & 50 & 100
\end{tabular}

Berdasarkan data Tabel 4 kader kesehatan desa siaga aktif yang berasal dari Desa Kedungboto dan Desa Peron Kecamatan Limbangan Kabupaten Kendal, sebagian besar menjadi kader selama 6 - 10 tahun sebanyak $30 \%$ (15 orang) sedangkan yang paling sedikit adalah kurang dari 1 tahun yaitu sebanyak $12 \%$ (6 orang)

Tabel.5 Distribusi frekuensi Responden Berdasarkan Keikutsertaan Pelatihan / Seminar tentang ASI

\begin{tabular}{ccc}
\hline $\begin{array}{c}\text { Keikutsertaan } \\
\text { Seminar } / \text { pelatihan } \\
\text { tentang ASI }\end{array}$ & $\begin{array}{c}\text { Frekuensi } \\
\text { (orang) }\end{array}$ & $\begin{array}{c}\text { Persentase } \\
(\%)\end{array}$ \\
\hline $\begin{array}{c}\text { Belum pernah } \\
\text { Sudah Pernah }\end{array}$ & 46 & 92 \\
\hline Total & 50 & 8 \\
\hline
\end{tabular}

Berdasarkan tabel 5 dapat diketahui bahwa Sebagian besar 92\% (46 orang) belum pernah ikut pelatihan atau seminar tentang ASI dan hanya 8\% (4 orang) yang sudah pernah ikut seminar tentang ASI

Tabel 6 Responden Berdasarkan Sikap Kader tentang ASI Eksklusif

\begin{tabular}{|c|c|c|c|}
\hline \multicolumn{2}{|c|}{ Sikap } & \multirow{2}{*}{$\begin{array}{c}\text { Frekuensi } \\
\text { (orang) }\end{array}$} & \multirow{2}{*}{$\begin{array}{c}\text { Persenta } \\
\text { se } \\
(\%)\end{array}$} \\
\hline Keterangan & $\begin{array}{c}\text { Rentang } \\
\text { Skor }\end{array}$ & & \\
\hline Buruk & $0-13$ & 0 & 0 \\
\hline Sedang & $14-26$ & 13 & 26 \\
\hline Baik & $27-39$ & 37 & 74 \\
\hline \multicolumn{2}{|c|}{ Total } & 50 & 100 \\
\hline
\end{tabular}


Berdasarkan data Tabel 6 dapat dijelaskan bahwa kader kesehatan desa siaga aktif yang berasal dari Desa Kedungboto dan Desa Peron Kecamatan Limbangan Kabupaten Kendal yang memiliki sikap tentang ASI Eksklusif tergolong positif atau baik dengan skor 2739 sebanyak 74\% (37 orang) dan hanya terdapat $26 \%$ (13 orang) yang memiliki sikap tentang ASI Eksklusif tergolong sedang atau cukup positif dengan skor 1426. Jadi dapat disimpulkan bahwa sikap kader kesehatan desa siaga aktif yang berasal dari Desa Kedungboto dan Desa Peron Kecamatan Limbangan Kabupaten Kendal tentang ASI Eksklusif tergolong baik atau positif.

Tabel 7 Responden Berdasarkan PraktikPenyuluhan ASI Eksklusif

\begin{tabular}{|c|c|c|c|}
\hline \multicolumn{2}{|c|}{ Praktik Penyuluhan } & \multirow{2}{*}{$\begin{array}{c}\text { Frekuensi } \\
\text { (orang) }\end{array}$} & \multirow{2}{*}{$\begin{array}{c}\text { Perse } \\
\text { ntase } \\
(\%)\end{array}$} \\
\hline Keterangan & $\begin{array}{c}\text { Rentang } \\
\text { Skor }\end{array}$ & & \\
\hline Buruk & $0-2$ & 0 & 0 \\
\hline Sedang & $3-5$ & 16 & 32 \\
\hline Baik & $6-8$ & 34 & 68 \\
\hline \multicolumn{2}{|c|}{ Total } & 50 & 100 \\
\hline
\end{tabular}

Berdasarkan data Tabel 7dapat

dijelaskan bahwa kader kesehatan desa siaga aktif yang berasal dari Desa Kedungboto dan Desa Peron Kecamatan Limbangan Kabupaten Kendal dalam praktik penyuluhan tentang ASI Eksklusif tergolong baik dengan skor 6-8 sebanyak $68 \%$ (34 orang) dan terdapat $32 \%$ (16 orang) yang praktik penyuluhan ASI Eksklusif tergolong sedang dengan skor 3-5. dari hasil penelitian didapatkan bahwa kader kesehatan desa siaga aktif yang berasal dari Desa Kedungboto dan
Desa Peron Kecamatan Limbangan Kabupaten Kendal dalam praktik penyuluhan ASI Eksklusif telah melaksanakan dengan baik.

Sebelum dilakukan analisis bivariat yang menguji hubungan antara pengetahuan dan sikap dengan praktik penyuluhan ASI Eksklusif kader kesehatan desa siaga aktif, terlebih dahulu dilakukan uji normalitas dengan uji Kolmogorov Smirnov. Jika data berdistribusi normal digunakan uji statistik parametrik korelasi Pearson, jika data berdistribusi tidak normal maka digunakan uji statistik alternatifnya yaitu korelasi Rank Spearman. Hasil uji normalitas variabel penelitian adalah sebagai berikut Tabel 8 Uji Normalitas

\begin{tabular}{|c|c|c|c|c|c|}
\hline $\begin{array}{c}\text { Variabel } \\
\text { Penelitia } \\
n\end{array}$ & $\begin{array}{l}\text { Kol } \\
\text { mog } \\
\text { orov } \\
\text { Smir } \\
\text { nov }\end{array}$ & $p$ & $\begin{array}{c}\alpha= \\
0,05\end{array}$ & $\begin{array}{l}\text { Kesi } \\
\text { mpul } \\
\text { an }\end{array}$ & $\begin{array}{c}\text { Uji Hipotesis } \\
\text { yang } \\
\text { digunakan }\end{array}$ \\
\hline $\begin{array}{l}\text { Sikap } \\
\text { kader } \\
\text { tentang } \\
\text { ASI } \\
\text { Eksklusif }\end{array}$ & $\begin{array}{c}0,15 \\
8\end{array}$ & $\begin{array}{l}0 \\
00 \\
3\end{array}$ & $\begin{array}{c}\mathrm{p}< \\
0,05\end{array}$ & $\begin{array}{c}\text { Tida } \\
k \\
\text { Nor } \\
\text { mal }\end{array}$ & $\begin{array}{l}\text { Korelasi } \\
\text { Rank } \\
\text { Spearman }\end{array}$ \\
\hline $\begin{array}{l}\text { Praktik } \\
\text { penyulu } \\
\text { han ASI } \\
\text { Eksklusif }\end{array}$ & $\begin{array}{c}0,21 \\
5\end{array}$ & $\begin{array}{l}0 \\
00 \\
0\end{array}$ & $\begin{array}{c}p< \\
0,05\end{array}$ & $\begin{array}{c}\text { Tida } \\
k \\
\text { Nor } \\
\text { mal }\end{array}$ & $\begin{array}{l}\text { Korelasi } \\
\text { Rank } \\
\text { Spearman }\end{array}$ \\
\hline
\end{tabular}

Hasil uji normalitas menunjukkan bahwa semua data penelitian berdistribusi tidak normal. Maka pengujian hipotesis yang digunakan adalah korelasi Rank Spearman. Hasil uji hipotesis penelitian dirangkum dalam penleitian ini. 
Tabel 9 Uji Hipotesis Penelitian

\begin{tabular}{|c|c|c|c|c|}
\hline $\begin{array}{l}\text { Variabel } \\
\text { Bebas }\end{array}$ & $\begin{array}{l}\text { Korel } \\
\text { asi } \\
\text { Rank } \\
\text { Spear } \\
\text { man }\end{array}$ & $p$ & $\begin{array}{l}\alpha= \\
0,05\end{array}=$ & Kesimpulan \\
\hline $\begin{array}{l}\text { Sikap } \\
\text { kader } \\
\text { tentang } \\
\text { ASI } \\
\text { Eksklusif }\end{array}$ & 0,419 & 0,001 & $\begin{array}{l}\mathrm{p}< \\
0,05\end{array}$ & $\begin{array}{l}\text { Ada } \\
\text { hubungan } \\
\text { positif yang } \\
\text { signifikan }\end{array}$ \\
\hline
\end{tabular}

Penjelasan hasil pengujian hipotesis penelitian adalah sebagai berikut :Sikap kader tentang ASI Eksklusif Pengujian hipotesis penelitian tentang hubungan dengan praktik penyuluhan ASI eksklusif kader kesehatan desa siaga aktif dengan menggunakan korelasi rank speramen diperoleh nilai korelasi 0,419 dengan nilai $p=0,001$ sehingga $p<0,05$ artinya ada hubungan yang signifikan antara sikap dengan praktik penyuluhan ASI Eksklusif kader kesehatan desa siaga aktif. Dari hasil penelitian ini menunjukan semakin positif atau baik sikap maka akan semakin baik pula praktik penyuluhan ASI Eksklusif yang dilakukan oleh kader kesehatan desa siaga aktif, sebaliknya semakin negatif atau buruk sikap maka akan semakin rendah pula praktik penyuluhan ASI Eksklusif yang dilakukan kader kesehatan desa siaga aktif.

Dari hasil pengujian uji hipotesis menunjukkan adanya hubungan yang signifikan antara sikap dengan praktik penyuluhan ASI Eksklusif kader kesehatan desa siaga aktif. Hal ini menunjukan bahwa semakin tinggi atau baik sikap maka akan semakin baik pula praktik penyuluhan ASI Eksklusif yang dilakukan kader kesehatan desa siaga aktif, sebaliknya semakin rendah atau buruk sikap maka akan semakin rendah pula praktik penyuluhan ASI Eksklusif yang dilakukan oleh kader kesehatan desa siaga aktif. Sikap berpengaruh secara signifikan terhadap tindakan kader dalam penyuluhan kesehatan tentang pedoman gizi seimbang untuk balita. Karena sikap merupakan cerminan dari persepsi seorang kader tentang pentingnya peranan kader dalam meningkatkan kualitas hidup ibu dan balita. ${ }^{(14)}$ Semakin baik sikap seorang kader tentang masalah kesehatan maka semakin baik pula praktik dan perilaku kader dalam memberikan penyuluhan atau pemahaman kepada masyarakat. Hasil penelitian menunjukan bahwa sikap kader tentang ASI eksklusif berhubungan secara signifikan terhadap praktik kader desa siaga aktif dalam memberikan penyuluhan ASI eksklusif.

Pemberan asi eklusif pada bayi baru lahir dapat mempengaruhi kelangsungan selanjutnya. pemebrian asi eklusif yang tepat menghindarkan bayi tumbuh mengami stunting. Stunting sangat merugikan dalam pertumbuhan dan perkembangan yang mengalami anak. stunting dapat dicegah dengan pemberian asi ekslusif yang adekuat.(Putri Azzahroh, 2018)

Sesuai dengan penelitian Wijaya 2013 bahwa pengetahuan,sikap dan 
motivasi kader kesehatan dipengaruhi oleh berbagai factor dalam melaksanakan praktik penyuluhan kesehatan. Kader dalam memberikan pelayanan kesehatan perlu mendapatkan bekal yang cukup berupa pengetahuan untuk menunjang sikap dan praktik yang akan dilaksanakan(Wijaya, 2013)

Untuk meningkatkan sikap dan motivasi kader kesehatan perlu diberikan dukungan dari berbagai pihak baik dari petugas kesehatan maupun dari pemerintah. Perhatian yang diberikan akan meningkatkan harga diri dan motivasi dalam memberikan pelayanan kepada masyarakat sekitar yang menjadi tugas dan wilayah pelayanan kader (Kiting, Ilmi and Arifin, 2017)

\section{KESIMPULAN}

Hasil penelitian dapat disimpulkan sebagi berikut:

1. Sebagian besar kader kesehatan Desa siaga aktif yang berasal dari Desa Kedungboto dan Desa Peron Kecamatan Limbangan Kabupaten Kendal tentang ASI Eksklusif memiliki sikap baik atau positif

2. Sebagian besar praktik penyuluhan tentang asi ekslusif dalam kategori baik pada Kader kesehatan desa siaga aktif yang berasal dari Desa Kedungboto dan Desa Peron Kecamatan Limbangan Kabupaten Kendal
3. Ada hubungan yang signifikan antara sikap dengan praktik penyuluhan ASI Eksklusif kader kesehatan desa siaga aktif. Semakin tinggi atau baik pengetahuan maka akan semakin baik pula praktik penyuluhan ASI Eksklusif yang dilakukan oleh kader kesehatan desa siaga aktif, sebaliknya semakin rendah atau buruk pengetahuan maka akan semakin rendah pula praktik penyuluhan ASI Eksklusif yang dilakukan oleh kader kesehatan desa siaga aktif. Disarankan agar kader kesehatan yang berada di desa siaga aktif terus meningkatkan motivasi masyarakat melalui penyuluhan kepada masyarakat untuk pemberian asi ekslusif dan penentu program mengadakan kegiatan seminar atau pelatihan tentang ASI Eksklusif sebagai bekal pengetahuan bagi kader kesehatan desa siaga aktif.

\section{DAFTAR PUSTAKA}

Hastuti, P. and Wijayanti, I. T. (2017)

'Analisis Deskriptif Faktor yang

Mempengaruhi Pengeluaran ASI pada Ibu Nifas di Desa Sumber Kecamatan Sumber Kabupaten Rembang',

Journal.Ummgl.Ac.ld. doi: 2407-9189.

Kemenkes RI (2013) 'Kehamilan, Persalinan, dan Nifas Normal', Buku Saku Pelayanan Kesehatan Ibu di Fasilitas Kesehatan Dasar dan Rujukan. doi: 10.1016/j.mcna.2016.06.004.Nutrition. 
Kiting, R. P., Ilmi, B. and Arifin, S. (2017)

'FAKTOR YANG BERHUBUNGAN

DENGAN KINERJA KADER POSBINDU

PENYAKIT TIDAK MENULAR', Jurnal

Berkala Kesehatan. doi:

10.20527/jbk.v1i2.3149.

Lestariningsih, S. and Budi Susila Duarsa,

A. (2013) 'HUBUNGAN PREEKLAMPSIA

DALAM KEHAMILAN DENGAN

KEJADIAN BBLR DI RSUD JENDERAL

AHMAD YANI KOTA METRO TAHUN

2011', Jurnal Kesehatan Masyarakat

Andalas. doi: 10.24893/jkma.8.1.34-

39.2013.

Putri Azzahroh, L. A. (2018) 'Analisis

Kejadian Stunting Pada Balita Di Desa

Pasirdoton Kecamatan Cidahu Kabupaten

Sukabumi Provinsi Jawa Barat Tahun

2017-2018', Jurnal Akademi Keperawatan

Husada Karya Jaya.

Suriani, S. (2017) 'Analisis Faktor

Kejadian Kematian Ibu di Kabupaen

Serang Banten', Prosiding Seminar

Nasional IKAKESMADA "Peran Tenaga

Kesehatan dalam Pelaksanaan SDGs".

Triyono, A. and Wibowo, Y. A. (2018)

'Strategi Komunikasi Pembangunan Tim

Promosi Kesehatan Puskesmas Polokarto

Melalui Program Desa Siaga', Jurnal

Komunikasi Global. doi:

10.24815/jkg.v7i1.10657.
Wijaya, I. M. K. (2013) 'Jurnal Kesehatan Masyarakat 2013', Pengetahuan, Sikap dan Motivasi terhadap Keaktifan Kader Dalam Pengendalian Tuberkulosis. doi: ISSN 1858-1196. 